\title{
TEXTOS LEGAIS E JURÍDICOS: O CUMPRIMENTO A PARTIR DE MAL- ENTENDIDOS E DE DIVERSAS INTERPRETAÇÕES
}

\author{
LEGAL AND JURIDICAL TEXTS: THE ACCOMPLISHMENT FROM \\ MISUNDERSTANDING AND SEVERAL INTERPRETATIONS
}

\author{
KAPPEL, Irma Beatriz Araújo \\ Universidade Federal do Triângulo Mineiro (UFTM/Uberaba) \\ araujokappel@terra.com.br
}

\begin{abstract}
Resumo
Este resumo refere-se aos primeiros estudos realizados na pesquisa "Linguagens Normativa e Jurídica nos Órgãos Públicos Educacionais: distinções e semelhanças" do Grupo de Pesquisa e Estudo em Lingüística e Língua Portuguesa (GPELLP/UFTM) e tem por finalidade demonstrar exemplos e provocar questionamentos quanto à diversidade das linguagens normativa e jurídica no que tange às decisões judiciais no país, em especial na área do Ensino Público; o que a norma e a interpretação da mesma podem causar; e a ideologia por trás do texto e da interpretação textual. Para isso, indagamos as condições de produção por partirmos do pressuposto de que o discurso é determinado pelos fatores sócio-histórico e ideológico que o constituem. Realizamos um estudo acerca da interpretação de dois textos normativos voltados aos direitos dos servidores da área educacional. Posteriormente, fizemos um confronto entre o que dizem algumas leis e como se dá a sua real aplicação. Concluímos que, uma vez considerado o discurso institucional legal como um lugar de conflito, a linguagem como uma atividade constitutiva, uma forma de ação entre os homens, essas leis tratam de valoração e conceituação materializadas nas práticas sociais, nos seus processos de significação e de representação coletiva. Desse modo, elas instituem balizas para o funcionamento social, que extrapolam os limites puramente jurídico-educacionais, o fato político e jurídico (a lei) e o fato lingüístico (o texto). Por isso, a análise que realizamos possibilitou um estudo não apenas lingüístico, mas também discursivo-ideológico do texto legal e sua aplicabilidade.
\end{abstract}

Palavras-chave: lei; benefício; interpretação; mal-entendido.

\begin{abstract}
This summary refers to the first studies accomplished in the "Normative and Juridical Languages research in the Educational Public Organs: distinctions and similarities" of the Research and Study Group in Linguistics and Portuguese Language (GPELLP/UFTM) and it has the purpose to demonstrate examples and to provoke enquiries regarding the diversity of the normative and juridical languages concerning to the judicial decisions in the country, especially in the area of the Public Teaching; what the same norm and the interpretation can cause; and the ideology behind the text and the textual interpretation. Thus, we investigated the production terms from the purpose which the speech is determined by the social-historical and ideological factors which constitute it. We accomplished a study concerning the interpretation of two normative texts to the rights of the educational area workers. Afterwards, we did one confront between some laws and how their real applications are. We conclude once it is considered the legal institutional speech as a conflict place, the language as a constituent activity, an action form among people, these laws deal with the values and materialized concepts in the social practices, in their significance processes and collective representation. Thus, they institute marks for the social operation which extrapolate purely the juridical-educational limits, the political and juridical fact (the law) and the linguistic fact (the text). Therefore, the analysis we accomplished enabled not just a linguistic study, but also discursive-ideological one of the legal text and its applicability.
\end{abstract}


Key-words: law; benefit; interpretation; misunderstanding.

\section{Introdução}

Este artigo aborda questões relevantes da pesquisa acerca das tipologias de textos legais e jurídicos nos órgãos públicos educacionais pertencente ao GPELLP/UFTM (Grupo de Pesquisa e Estudos em Lingüística e Língua Portuguesa da Universidade Federal do Triângulo Mineiro) a fim de investigar quais os efeitos de sentido dos textos produzidos com a finalidade de legalizar o bem comum; como a interpretação de um texto legal (constituído de um código lingüístico) pode representar um instrumento de controle; quais as contribuições que o conhecimento acerca dos elementos tipológicos (texto/discurso) podem trazer para a solução de questões legais na vida das pessoas e a influência do poder estatal em dar definições que contrariam até a legislação superior.

Considerando a linguagem a partir de seu uso social, como recurso estratégico para a construção de sentido, e sendo o texto uma unidade produtora de significação, pretendemos verificar, com base na Análise do Discurso de vertente francesa, como o texto legal pretende se instaurar um texto objetivo e de interpretação definida e quais recursos são utilizados para esse intento. Ao fazer essa análise verificar-se-á se textos desse tipo poderiam estar contribuindo para a manutenção de uma ideologia de domínio do forte sobre o fraco, do interesse do poder econômico, patronal, governamental e político, acima do profissional e do bem comum.

Ocorrendo dualidade na interpretação do texto legal, ocorrerá o que denominamos de mal-entendido na interpretação desse tipo de texto. Por isso, este trabalho procurará se fundamentar na Análise do Discurso por se tratar de uma teoria lingüística que se propõe a buscar o que de social, ideológico e histórico é constitutivo da linguagem e que, sobretudo, coloca a ação lingüística ao lado da ação não-lingüística, de modo a compreender o ato lingüístico simultaneamente ao ato social, histórico e ideológico a fim de perceber o porquê do mal-entendido.

A questão posta em relevo pela AD é a consideração dos discursos constitutivos da linguagem. Uma teoria lingüística que leve em conta não apenas os enunciados produzidos, mas o evento particular que produziu a enunciação é, ao nosso ver, a base sólida para uma tentativa de análise de um texto normativo, cuja interpretação é dada a partir de um mal-entendido. 
Serão discutidas as diferentes formações discursivas na elaboração e interpretação de textos legais, enfocando aspectos lingüísticos, sociais, econômicos, políticos, históricos e ideológicos na redação e na interpretação de alguns artigos acerca do direito trabalhista - tempo de serviço para aposentadoria - do servidor público.

Assim como os estudos da linguagem, a Ciência Jurídica perdeu suas posturas tradicionais e positivistas nos últimos decênios. A concepção de uma ciência neutra e objetiva cede lugar à concepção de uma ciência marcada pela provocação constante de tensão - na elaboração, no entendimento e na execução - e pelo conflito das normas, as quais, em alguns casos, utilizam-se de uma linguagem suscetível à vagueza e à ambigüidade.

Uma vez considerado o discurso institucional legal como um lugar de conflito, o texto legal deve ser compreendido e estudado a partir de uma visão da Análise do Discurso, que vê a linguagem como uma atividade constitutiva, uma forma de ação entre os homens (persuasão e convencimento). A inscrição do discurso educacional-legal apresenta, na realidade sócio-histórica, a instituição de valores, crenças, comportamentos, atitudes e conceitos nos quais se encontra presente o modo de produção de (seus) sentidos que devem ser assumidos pela sociedade.

Essas leis tratam de valoração e conceituação materializadas nas práticas sociais (com destaque à área educação), nos seus processos de significação, de representação coletiva. Desse modo, elas instituem balizas para o funcionamento social, que extrapolam os limites puramente jurídico-educacionais, pois o fato político e jurídico (a lei) e o fato lingüístico (o texto ) estão sempre interligados.

Este estudo permitirá que se tragam à luz, mediante um olhar crítico sobre os enunciados representativos de um Discurso Institucional Legal (SANTOS, 2000), os discursos nem sempre explícitos e freqüentemente contraditórios que se encontram num texto legal. Além disso, por meio da análise discursiva, poderemos ainda perceber como a realidade é ideologicamente representada.

Para alcançar esses objetivos, faremos uma pesquisa analítico descritiva e interpretativista porque investiga manifestações discursivas produtoras de sentido. Essa opção se justifica pela utilização do córpus documental para examinar nuanças da produção de sentidos. É qualitativa porque ao córpus documental escolhido será conduzida uma análise de suas propriedades fomentadoras de significação. Ela é, também, interpretativista porque o percurso de estudo das trajetórias de significação dos sentidos emerge a partir de uma visão teórica. Por fim, ela é analítico-descritiva porque 
estabelecerá recortes específicos nas manifestações discursivas em estudo com o intuito de caracterizá-los e examiná-los no crivo da ótica teórica adotada.

Realizamos um estudo acerca da interpretação de dois textos normativos em que parte desses textos se volta aos direitos à aposentadoria dos servidores da área educacional, a Emenda à Constituição Federal n 20, de 1998 e Emenda à Constituição Estadual $n^{\circ} 57$, de 2003. Para esse estudo, selecionamos, em princípio, os seguintes documentos: Constituição da República Federativa do Brasil, de 1988; Parecer do Tribunal de Contas da União, por meio da Decisão $n^{\circ} 748 / 2000$, publicada no DOU $n^{\circ}$ 188, em 28 de setembro de 2000; Manual de Redação Oficial da Presidência da República, de 2002; Instrução n 02/03 da Superintendência Central de Administração e Pagamento de Pessoal /MG; e Decreto $n^{\circ}$ 43.764, de 2004 emitido pelo governador do Estado de Minas Gerais. Posteriormente, fizemos um confronto entre o que dizem determinadas emendas constitucionais e como se dão a sua real aplicação.

Ferraz Jr. (1980, p.76), ao discutir o problema da interpretação das normas sob a luz da Ciência do Direito (vista como Teoria da Interpretação), observa que a "interpretação gramatical é, pois, apenas ponto de partida, e nunca ou quase nunca um fim de processo", mas complementa que "ao lado da interpretação vocabular (gramatical), o jurista se vê obrigado, para obter um sentido razoável, a valer-se de técnicas de objetivos mais amplos, que buscam, então, o sentido contextual da norma".

Por entendermos os textos legais como locus da significância, que institui formas, formações e formulações significativas, eivando sentidos e efeitos numa dimensão suprareal que se constrói não nas leis propriamente ditas, mas nas relações que se travam na sociedade, situadas temporal e espacialmente, provindas das experiências vividas (imaginárias ou reais) pelos indivíduos dessa sociedade, em relação aos efeitos de sentido provenientes de tais discursos é que optamos por realizar esta pesquisa.

\section{2- Um breve comentário sobre pontos necessários da ciência da linguagem}

Nas últimas décadas, a concepção de ciência neutra e objetiva cede lugar à concepção de uma ciência marcada pelo conflito das normas, a qual se utiliza, em alguns casos, de uma linguagem suscetível à vagueza e à ambigüidade.

Para isso, foi fundamental a consideração do "papel do social" na redefinição do objeto da ciência da linguagem. A língua por ser um sistema simbólico torna-se significativa ao remeter a um sistema de referências, produzido nas relações interativas 
que, por seu turno, situam-se numa determinada formação social e são por esta marcadas. Daí compreender a linguagem como trabalho constitutivo dos sistemas de referências e dos sujeitos cujas consciências se formam precisamente pelo conjunto de categorias que vão incorporando, enquanto signos, nos processos interlocutivos de que participam (GERALDI, 1990).

A inscrição de normas para definição de benefícios trabalhistas apresenta, na realidade sócio-histórica, a instituição de valores, crenças, comportamentos, atitudes e conceitos nos quais se encontra presente o modo de produção de (seus) sentidos que são assumidos pelo grupo social interessado.

Como é por meio da linguagem que a norma se constitui e sendo a linguagem uma forma de ação e interação entre os indivíduos em seu meio social, esse texto delega poder para que uma pessoa possa agir sobre a outra, ou um grupo possa agir sobre o outro, por meio da ação lingüística, tentando mudar o pensamento, atitudes e até impor condutas. Inserida no contexto sócio-histórico do indivíduo, a linguagem é um lugar de confronto ideológico, que se estabelece pela propriedade que um discurso pode ter de exercer influência sobre o destinatário. BARTHES (1978) enfatizou essa relação, linguagem-poder, afirmando: "o poder é o parasita de um organismo trans-social, ligado à história inteira do homem (...): a linguagem".

A natureza social da linguagem a torna um objeto ideológico, como afirmou BAKHTIN (1998, p.36). As normas, materializadas pela linguagem por meio da palavra, inserem-se no processo histórico-social e são extraídas da experiência de vida em sociedade, mas têm elaboração conceitual, ideológica e teórica. Tendo a normalidade social da conduta do homem e o controle social como elementos ínsitos do ser social, as normas potencializam e, muitas vezes, instrumentalizam a ação de instituições.

É da práxis social que surgem as normas: comunicações intersubjetivas normativas. Essa práxis, ao receber os influxos das ideologias e de instrumentos de burocratização, tende a tornar-se predominantemente uma técnica operativa. Por isso, a questão do conhecimento das normas exigirá uma visão de cunho sociológico-histórico, além do lingüístico, e, simultaneamente, uma visão de caráter crítico-prospectivo, que questione constantemente suas formas de aplicação, dado que a existência social, na qual a norma incide e decide, não é estática, mas mutável e dinâmica, é um processo, está se constituindo.

Há que se considerar também, que as palavras não têm realidade fora da produção lingüística, pois elas existem nas situações nas quais são usadas, daí a importância do contexto para a construção do sentido. E é neste e por esse olhar que a linguagem 
jurídica deve ser enfocada: não como algo estanque, pronto, acabado e imutável, mas como uma reflexão da estrutura de uma língua viva, pertencente a toda uma sociedade .

Um ponto essencial para nossa análise é estabelecer as condições que caracterizam e constituem o discurso, no caso específico o discurso do texto legal, nosso objeto de análise. Para a Análise do Discurso não há um sujeito que se apropria da linguagem, mas uma forma social de apropriação na qual está refletida a ilusão do sujeito, ou sua interpelação feita pela ideologia.

O texto institucional legal é constituído por palavras selecionadas para veicular uma realidade material. Como a complexidade de uma luta política se instaura em qualquer disputa pelo poder, esse tipo de texto explicita os valores, as idéias e as representações tidas como universais, as quais, porém, tentaremos mostrar que são próprias de certos grupos sociais. Os órgãos institucionais (Aparelhos de Estado, conforme Althusser, 1980) compreendem, em suas estruturas hegemônicas, formações sociais antagônicas que se materializam em processos de interpelação distintos. Nas instituições tidas como neutras, o caráter pode ser verificado, pois elas estão sujeitas à influência de quem patrocina, de quem participa.

A Análise do Discurso define a natureza dos processos discursivos e enunciativos por meio da articulação entre a Lingüística e a Teoria Histórica dos processos de formações sociais. Nosso enfoque será o campo discursivo do discurso institucional legal: artigos acerca da consideração do tempo ficto para aposentadoria do servidor público, citados ou silenciados na Emenda à Constituição Federal $n^{\circ} 20$ e à Emenda à Constituição do Estado de Minas Gerais n 57.

Por "espaço discursivo" (MAINGUENEAU, 1993) entende-se o espaço no interior do qual é delimitado o córpus. Nele consideraremos as esferas política, institucional legal e educacional, porque é nesses campos (e primeiro deles) que se determinam os direitos e deveres, as responsabilidades e as cobranças.

Sob o ponto de vista da intertextualidade, podemos encontrar nos textos legais um vocabulário institucional, que circunscreve uma noção complexa, a qual procuraremos mostrar, por meio do recurso lingüístico da paráfrase (FUCHS,1982), ser muito mais ideológica e política do que jurídica: as leis, mesmo reformuladas, podem preservar ou omitir o interesse de classes num jogo de representações.

A noção de paráfrase é trazida por Orlandi (1987, p.136-137) como a própria condição de existência da linguagem. Para essa autora, a linguagem se constitui na tensão entre dois processos: a paráfrase e a polissemia. Aquela mantém o homem num retorno constante a um mesmo espaço dizível; esta desloca o "mesmo" e aponta a ruptura 
em direção à criatividade, revelando o conflito entre o institucionalizado e o que tem que se instituir. O conceito de paráfrase também é analisado por Fuchs (1981, destacando 1982 em La Paraphrase entre la Langue et le Discours , 1985, 1994).

\section{3- O Mal-Entendido na Interpretação do Texto Legal}

Os chamados mal-entendidos, ou problemas de comunicação, surgem, geralmente, nas interações verbais do dia-a-dia, nas quais a diversidade lingüística atua como um recurso comunicativo de forma a permitir que os interlocutores se baseiem em conhecimentos e paradigmas relativos às diferentes maneiras de articulação da língua para categorizar eventos, inferir intenções e antever situações que poderão ocorrer. Dessa forma, uma elocução pode ser entendida de diferentes modos, as pessoas podem interpretar uma determinada elocução com base em suas definições ou percepções do que está acontecendo no momento da interação, num dado contexto histórico-social.

Concordando que a "arbitrariedade" resulta do fato de haver uma relação entre o discurso e o sistema de produção no qual existe, entendemos que a teoria do malentendido no texto oral, proposta por GUMPERS (1989, p. 190), na interação verbal, se adaptada, pode ser perfeitamente aplicada ao texto escrito, tendo em vista as várias interpretações que surgem de um mesmo texto, servindo assim, aos nossos propósitos de análise.

Nessa perspectiva, adotamos o texto como uma unidade de sentido, dado por um efeito ideológico da posição do autor, assim como a interpretação do texto resulta de um efeito ideológico da posição do leitor, ou, no caso, do grupo governamental responsável pela interpretação do texto.

GUMPERS (1989) propôs alguns procedimentos que serviram para identificar estratégias de interpretações disponíveis aos falantes, seguindo as pistas de contextualização, que se apresentam na forma dos traços lingüísticos ou não lingüísticos que contribuem para assinalar as pressuposições contextuais. Assim, de acordo com esse autor, é possível, a partir dessas pistas, conhecer as causas do mal-entendido, ou os problemas de comunicação.

Da pesquisa de Gumpers, depreendemos, para a análise dos textos em questão, a possibilidade de adaptar a interpretação do texto oral às questões que dizem respeito ao texto escrito através das marcas, ou pistas lingüísticas, que neles se circunscrevem. Nossas reflexões se darão em torno de um texto jurídico que tenta usar uma linguagem 
objetiva e neutra, mas que, assim procedendo, abre espaços para entendimentos diversos e contraditórios, ou seja, o mal-entendido.

\section{Análise do córpus}

Os textos selecionados, a Emenda à Constituição Federal n² 20, de 1998; Emenda à Constituição Estadual $n^{\circ}$ 57, de 2003; Parecer do Tribunal de Contas da União, por meio da Decisão n 748/2000, publicada no DOU n 188, em 28 de setembro de 2000; Manual de Redação Oficial da Presidência da República, de 2002; Instrução n 02/03 da Superintendência Central de Administração e Pagamento de Pessoal /MG; e Decreto $n^{\circ}$ 43.764, de 2004 emitido pelo governador do Estado de Minas Gerais, serão considerados enunciados (materialização lingüístico-discursiva dos sentidos) de um Discurso Institucional Legal constituído por uma multiplicidade de vozes que revelam o imaginário sociodiscursivo dos sujeitos (SANTOS, 2000).

Esses textos apresentados neste artigo como objeto de análise estão inseridos numa variedade lingüística veicular e enunciado por um grupo que define o poder no Estado por meio de textos legais. Uma classe que impõe as suas ordens e possui instrumentos de normatização elaborados pela norma padrão, baseando-se em dicionários, gramáticas, manuais. O discurso aqui analisado pertence à língua oficial, ou seja, à variedade padronizada. Tal variedade encontra-se objetivamente associada ao sistema de valores, aos objetivos e aos interesses de grupos dominantes, no caso, o Governo de Minas Gerais.

Baseando-se na Constituição Federal, promulgada em 1988, há que se obrigatoriamente contextualizar a norma, ou seja, trazê-la para a atualidade a fim de que se promova a justiça, ação que deve ser tomada, inclusive, com base no que diz o Manual de Redação da Presidência da República: “ A redação oficial deve caracterizar-se pela impessoalidade (se é que a impessoalidade seja possível) ${ }^{1}$, uso do padrão culto de linguagem, clareza, concisão, formalidade e uniformidade." [...] "As comunicações que partem dos órgãos públicos devem ser entendidas por todo e qualquer cidadão brasileiro." Atrelada ao sentido contextual, retomamos a questão da interpretação vocabular como co-participativa na adequada leitura de sentido de uma norma, na qual um desvio gramatical pode modificar a sua real definição.

Ao interpretar um texto legal, é preciso perguntar como, por quê, para quê baseado em quê e até mais, em que condições de produção ? Porém, a linguagem

\footnotetext{
${ }^{1}$ Observação nossa.
} 
normativa nem sempre se faz clara e compreensível a ponto de dar respostas para tais questões, possivelmente tornando-se, assim, fonte de graves enganos. Caso exemplar para este contexto, é o suposto engano de interpretação, suscitado e publicado por KAPPEL et al. (2001), a partir do texto da Emenda Constitucional de $\mathrm{n}^{\circ} 20$, de 1998 (que modifica o sistema de Previdência Social), quando o Artigo $3^{\circ}$, referindo-se ao Artigo 40 da Constituição Federal, Parágrafo 10, reza o seguinte:

É assegurada a concessão de aposentadoria e pensão, a qualquer tempo, aos servidores públicos e aos segurados do regime geral da previdência social, bem como aos seus dependentes, que, até a data de publicação desta emenda, tenham cumprido os requisitos para a obtenção destes benefícios, com base nos critérios da legislação vigente. (Emenda à Constituição ${ }^{\circ} 20$ ).

[...] A lei não poderá estabelecer qualquer forma de contagem de tempo de contribuição fictício (Artigo 40 da Constituição).

Uma classe lesada, neste caso, foi a dos professores do Ensino Público do Estado de Minas Gerais e dos servidores, que por mérito, acumularam um benefício denominado "férias-prêmio" e que contabilizavam (quando não usufruídas ) como tempo de serviço dobrado para a aposentadoria.

No entanto, figurando um mal-entendido, a Secretaria de Administração do Estado de Minas Gerais (órgão que orienta a concessão de benefícios à classe) redigiu, em 1999 que vigorou até 2003, um texto que tece comentários acerca da interpretação que esse órgão fez quanto ao Artigo $3^{\circ}$ da citada Emenda Constitucional: "Apenas as pessoas que preenchiam os quesitos para se aposentarem antes da publicação da Emenda é que poderiam contar em dobro as férias-prêmio adquiridas e não usufruídas, como tempo de serviço para aposentadoria."

Como houve dúvidas em relação ao entendimento, o Presidente da Câmara dos Deputados, Michel Temer, fez uma consulta ao Tribunal de Contas da União a respeito da utilização do tempo ficto, tendo em vista dois entendimentos: só quem tivesse o direito adquirido para se aposentar em 1998 é que poderia contar o tempo ficto - férias-prêmio em dobro - ou quem as adquiriu até 1998, direito adquirido, é que poderia contar em dobro na época da aposentadoria.

Em 2000, o Tribunal de Contas da União entendeu que é assegurada, ao servidor, a contagem em dobro das férias-prêmio não usufruídas, ainda que ele não contasse tempo suficiente para se aposentar até a data da publicação da Emenda. A conjunção "ainda que", segundo Kappel et al, (2001) dá abertura e amplia o direito ao 
tempo ficto adquirido antes da Emenda, a ser considerado em qualquer época, desde que não tenha sido usufruído.

Mesmo com a publicação da Decisão 748/2000 expondo o parecer do Tribunal de Contas da União, com o entendimento de que todas as férias-prêmio adquiridas até 1998 poderiam ser contadas em dobro para a aposentadoria, o estado de Minas Gerais, priorizando o "Pacto de Gestão" que previa a redução dos gastos com o servidor público, dentre outros, continuou indeferindo pedidos de aposentadorias aos solicitantes que se utilizavam desse tempo.

Só a partir de julho de 2003, após a publicação de uma nova Emenda Constitucional do Estado de Minas Gerais, a de $n^{\circ}$ 57, que diz em seu artigo 115: É garantida a contagem em dobro das férias-prêmio não gozadas: para fins de concessão de aposentadoria, as férias-prêmio adquiridas até a data da publicação da Emenda à Constituição $n^{\circ}$ 20, de 15/12/98 [ ... ] é que esse tempo pôde ser considerado. Dessa forma, apenas em 2003 é que se respeitou o direito adquirido dos professores e servidores públicos do estado de Minas Gerais.

Por um mal-entendido na interpretação do texto legal ficou retido o direito à aposentadoria de vários membros dessas classes, que não questionaram, que "confusos" não puderam compreender o que a lei instituía, continuaram trabalhando, desconsideraram o seu tempo de férias-prêmio em dobro adquiridas antes de 1998 e dois, três, quatro ou quase cinco anos depois de excessivo trabalho e/ou regência escolar contada efetivamente como tempo de serviço para a aposentadoria, deram início então, aos seus processos para obtenção de tal benefício, ou melhor, de um direito.

Mesmo tendo uma Lei Federal com Parecer do Tribunal de Contas da União, o estado de Minas Gerais levou cinco anos para ter o mesmo entendimento que a Lei Magna. Somente a partir de julho de 2003 é que todo professor ou servidor do estado de Minas Gerais, que detinha o direito de férias-prêmio em dobro, pôde utilizá-lo para aposentadoria, permanecendo em serviço em até cinco anos à espera do entendimento adequado da interpretação da lei.

A Constituição Federal, após 1998, neste quesito, não foi alterada. Por que a Constituição do Estado de Minas Gerais só em 2003 passou a ter o mesmo entendimento e ainda precisou registrar esse entendimento em uma Emenda Constitucional? Redigindo em uma Emenda Constitucional em 2003, Minas Gerais estaria isenta de indenizar o período trabalhado indevidamente de 1998 a 2003, os servidores que detinham esse direito? 
O Discurso Institucional Legal (DIL), ponto central deste trabalho, é produzido por uma instituição federal e por uma instituição estadual que, sob a autoridade do Poder Executivo, com o objetivo de definir normas, dentre elas, o direito à aposentadoria aos seus servidores, infringiu uma lei superior. Visando aos objetivos de análise propostos, entendemos como em um DIL, os efeitos de sentido estabelecem parâmetros sobre a concepção e o funcionamento de um espaço discursivo - a existência de um desejo político - por meio de elementos normativos que condicionam a instauração ou não desse espaço discursivo, legitimando ou não sua influência e constituindo relações de poder, em diferentes lugares.

Para garantia no espaço discursivo das reformas previdenciárias, desencadeia-se uma cascata: a Constituição Federal faz surgir outras leis e regulamentações que se multiplicam em outras normas hierárquicas de âmbito Federal, Estadual e Municipal que deveriam ser automáticas, mas, na prática, podem ocorrer depois de vários anos.

O DIL é constituído por vozes que revelam o imaginário sociodiscursivo dos sujeitos enunciadores e incluem a imagem do público a quem se destina a lei - o povo brasileiro, que nem sempre é respeitado.

\section{Considerações finais}

Podemos considerar que há tendências, interesses, incompletudes, que podem partir do grau de interesse, de particularismo, que chegam a distorcer os fatos e alterar o dispositivo normativo quando, para a atualização do texto ou interpretação do mesmo, o sujeito receptor é lançado em um mecanismo de atribuição de sentido. Antes de tal leitura, pelo próprio contexto, o indivíduo, diante da criação de uma expectativa de sentido, especializa a sua procura no nível das informações memorizadas. Nesse contexto, o indivíduo, ao atualizar um texto ou interpretá-lo, por possuir uma certa gama de significados prévios para a leitura, tem a tendência a estender seus "pré-juízos" sobre a mensagem, moldando-a às suas expectativas. Traduzindo, então, pelo preconceito, pelo pré-julgamento, o seu entendimento do discurso, transformando-o em juízo de valor.

A Emenda de $n^{\circ} 20$ à Constituição Federal não foi alterada nesse aspecto após sua promulgação em 1998. Por que então, no Estado de Minas Gerais, redigiu-se o artigo 115 da Emenda à Constituição Estadual de $n^{\circ} 57$ para garantir uma interpretação igual à emitida pelos órgãos representativos do governo federal em 1999, de acordo com o 
Parecer do Tribunal de Contas da União, se a interpretação do estado de Minas Gerais de 1999 a 2003 foi diferente?

Perceber no discurso que se pretende neutro, o valor argumentativo de marcas, analisadas por Kappel et al (2001), é, sem dúvida alguma, o primeiro passo para desestabilizar o mal-entendido que nele se apresenta. Assim, concordamos com a tese de ANSCOMBRE; DUCROT (1976) e VOGT (1977) de que as instruções codificadas, de natureza gramatical, estão carregadas de argumentatividade e seu significado se atualiza a partir das estratégias utilizadas para permitir leituras que mascaram, sob a máscara da neutralidade, a intenção de limitar os direitos de uma classe. São justamente os morfemas que a gramática tradicional considera como elementos meramente relacionais e que a semântica argumentativa recupera, por considerá-los marcas lingüísticas importantes, é que vão determinar o valor argumentativo e sem nenhuma neutralidade do texto analisado.

A sobrevivência do homem em sociedade é relativa, pois cada pessoa depende das relações de poder que os outros estabelecem como critério de convivência. Perceber essa relação de poder, por meio do uso da linguagem, é olhar o aspecto lingüístico e o contexto social, histórico e ideológico.

\section{Referência bibliográfica}

ANSCOMBRE, J.; DUCROT, Osvaldo. 'L' argumentation dans la langue" In: Langages 42. Paris: Didier-Larousse, 1976, p.5-27.

BAKHTIN, Mikhail. Marxismo e filosofia da linguagem, São Paulo, SP: Hucitec, 1998.

BARTHES, R.. Aula. São Paulo: Cultrix,1978.

BRASIL, Constituição da República Federativa.Ed.Saraiva,1999.

, Emenda à Constituição n 20, 1998.

. Parecer do Tribunal de Contas da União,. In Decisão $n^{\circ} 748$. DOU no 188, de 28 de setembro de 2000.

, Manual de Redação da Presidência da República, 2002.

FERRAZ JR, Tércio Sampaio. A Ciência do Direito. São Paulo: Atlas, 1980.

FUCHS, C. La Paraphrase. Paris, P.V.F., 1981.

33, 1982.

"La paraphrase entre la langue et le discours". Langue Française, n. 53, p. 23- 
GERALDI, João Wanderley. Linguagem, interação e ensino. 1990. Tese (Doutorado). UNICAMP, Campinas, 1990.

GUMPERS, Jonh. Enganger la conversation: introuction à la sociolinguistique interacionalle. Paris: Éditions de Minuit, 1989.

KAPPEL, Irma Beatriz Araújo et al. Construção, Destruição e $(R e)$ Construção do Sentido. Uberaba: Revista Jurídica Unijus, 2001 , p. 99-110.

MAINGUENEAU, Novas Tendências em Análise do Discurso. 2. ed. Campinas: Pontes. (trad. de Nouvelles tendances en analyses du discours), 1993.

MINAS GERAIS, Emenda à Constituição $n^{\circ}$ 57, 2003.

de Pessoal/MG.

Instrução $n^{\circ}$ 02/03 da Superintendência Central de Administração e Pagamento . Decreto $n^{\circ} 43.764$, de 2004.

ORLANDI, Eni P. A linguagem e seu funcionamento. Campinas: Pontes, 1987.

SANTOS, João Bôsco C. Por uma teoria do discurso universitário institucional. 2000. Tese (Doutorado)- UFMG, Belo Horizonte, 2000.

VOGT, Carlos. O intervalo semântico. São Paulo: Ática, 1977. 